\title{
Organizational Resources, Industry Velocity, Attention Focus and Firm's Performance: A Review of Literature
}

\author{
Paul G. Kimiti ${ }^{1} \&$ James M. Kilika ${ }^{2}$ \\ ${ }^{1}$ Doctoral Student, Department of Business Administration, School of Business, Kenyatta University, Kenya \\ ${ }^{2}$ Lecturer, Department of Business Administration, Kenyatta University \\ Correspondence: James M. Kilika, Department of Business Administration, School of Business, Kenyatta \\ University. Kenya. E-mail: kilikam3@yahoo.com
}

Received: February 21, 2018

Accepted: March 10, 2018

Online Published: April 18, 2018

doi:10.5539/ijbm.v13n5p185

URL: https://doi.org/10.5539/ijbm.v13n5p185

\begin{abstract}
The study addressed the diverse views on the role of organizational resources in firm performance in high velocity industry context. It adopted a multidisciplinary approach to examine the linkage among organizational resources, industry velocity, attention focus and firm performance. It found that resource based advantages are rather transient in highly dynamic environments hence need to constantly adapt the internal factors through firm capabilities. The influence of the external environment on resource application decisions is however partial as only a portion of the environment is actually perceived and interpreted by strategic decision makers through the selective cognitive process of attention focus. These findings have implications for a better understanding of the constructs and how they are related as contained in the proposed theoretical framework. The paper proposes that future studies be based on wider multidisciplinary approaches and the proposed theoretical framework be applied in guiding empirical research in high velocity industries.
\end{abstract}

Keywords: Organizational resources, performance, industry velocity, high velocity industry context

\section{Introduction}

Performance of organizations is a common theme in strategic management. Contemporary strategic management is however infused by the concept of strategic thinking to address the handicap in the traditional strategic planning viewed as only functioning in stable environments (Hamel \& Prahalad, 1994). Three streams of strategic decision making exist; normative model emphasizing both external environment and internal conditions; strategic choice emphasizing the role of executives, and; the external control perspective which underscores the impact of external environment on strategic decisions making (Hitt \& Tyler, 1991). Regardless of the stream adopted by managerial teams in strategic decision making, it is clear across the streams that the strategies formulated lead to employment of certain organizational resources to attain firm's objectives.

The contribution of resources to firm performance has been studied since late 1950s (Penrose, 1959) with several authors concurring in considering resources to be the source of superior business returns (Wernerfelt, 1984; Barney, 1991; Amit \& Schoemaker, 1993) as advanced by the resource based view. This inward looking perspective to attain competitive advantage has however been criticized for failing to consider the external environment within which firms operate. In high velocity industry contexts particularly, it is necessary to go beyond the resource based view to explain firm performance since such contexts are characterized by high levels of unpredictability (Kraaijenbrink, Spender, \& Groen, 2009). Strategic decision making in such environments can be seen to proceed through two steps comprised of resource configuration and development stages tempered by the effect of dynamic complexity (Kunc \& Morecroft, 2010).

Consequently, managers cannot escape from considering environmental dynamism during formulation of strategies to employ resources. Environmental dynamism is a key characteristic of high velocity industry and represents the pace and nature of external change (Goeltz, 2014). These conditions however present challenges in decision making as the change is so dramatic and its significance is difficult to predict (Sutton, Eisenhardt, \& Jucker, 1986). This leads to excessive environmental information which in turn creates a dilemma of making strategic mistakes by acting too soon or being ineffective by delaying decision making. To assist navigate through the information and make effective decisions, managers rely on subjective representations of the 
environment through the cognitive process of attention focus rather than a complete understanding of their environments (Nadkarni \& Barr, 2008).

Attention focus allows managers to attend to some environmental information and ignore others. In addition, Cho and Hambrick (2006) argued that attention focus determines which environmental events will make it into the firm's strategic agenda. Managerial cognition itself is influenced by industry characteristics which affect how a firm applies its resources for superior performance. Industry characteristics describe the industry within which firms operate in terms of number and size of firms, level of competition, degree of volatility, industry performance among others (Papadakis, Lioukas, \& Chambers, 1998; Sveikauskas \& Sveikauskas, 1982). They also influence both resources availability and their competitive value and determine firm behavior and strategy formulation. Bourgeois and Eisenhardt (1988) for example found that effective firms in stable environments followed the rational model in decision-making but the same approach has been found not to be effective in unstable, high velocity industries characterized by information ambiguity and unpredictable change.

In spite of the foregoing suggested linkages among the constructs in this study, the available literature presents several occasionally contradicting schools of thought. Firstly, despite general consensus that organizational resources influence firm performance (Pearce, Robinson, \& Mital, 2012), some scholars view such resource based competitive advantages as transient rather than enduring due to context variation. This leads to divergence of ideas as to how resources contribute to competitive advantage with some researchers suggesting that firm performance relies on both the resources and the context under which it operates while others regard resources as a sufficient condition for superior performance. In reflecting on this view, it becomes crucial to examine literature on context based resource application by firms, how firm context is perceived and interpreted in applying internal factors and the resultant performance levels. Secondly, there is lack of scholarly coherence on the type of resources considered most critical to performance and whether environmental factors and managerial cognitive processes have a role in such determination. Srivastava, Shervani and Fahey (1998) for example argued that market-based resources were the most important while Ismail, Rose, Uli and Abdullah (2012) proposed these to be the human and intangible resources hence a need for further literature review.

Thirdly, in considering the firm environment and decision making, diversity of scholarly ideas on the segment to lay cognitive focus abound. Nadkarni and Barr (2008) advocated for more focus on the external environment, Learned, Christensen, Andrews and Guth (1965) called for balanced focus between internal and external environment while Selznick (1957) contended that managerial focus should be on firm competences. Bourgeois and Eisenhardt (1998) on the other hand portrayed attention focus as only applicable to decision making in dynamic external environments while arguing that managers of firms operating in stable environments adopted rational decision making models. This debate has continued to the recent past with Rose, Abdullah and Ismad (2010) arguing that the external environment does not influence performance while Huczynski and Buchanan (2013) postulated that an organization must interact with its environment. There is therefore need to explore literature to identify how the firm context is related to managerial cognitive focus and how this interaction influences resource application decisions.

In addition, even though several studies preceding the current one have been done (Ensley, Pearce \& Hmieleski, 2006; Nadkarni \& Barr, 2008; Cho \& Hambrick, 2006; Bourgeois \& Eisenhardt, 1988; Nadkarni \& Herrmann, 2010), the constructs have been conceptualized differently and the authors did not come across a study that has used interaction between industry velocity and attention focus as a contingent factor while examining the relationship between organizational resources and firm performance. Further, no empirical study seems to have been mounted using all the constructs so as to comprehensively explore and explain the complex phenomena emanating from the interaction of the constructs thus pointing to not only existence of an empirical but also a theoretical gap. This obtaining situation may partly be attributed to shallowness in focus embraced at both empirical and theoretical attempts to incorporate the constructs in a single research.

From the foregoing, integration of organizational resources, industry velocity, attention focus and firm performance emerges as a relevant area for further academic scrutiny. These constructs have been widely studied in various combinations but not all together with different findings arrived at by various scholars. Consequently, this restricted scope by previous studies presents lack of a broad theoretical model to explain the emergent phenomena. Due to the diversity of the constructs and their richness in diverse theoretical anchorage, a suggestion to examine the relevant diverse theories arises so as to provide broad theoretical underpinnings that would not only describe the constructs and their indicators but also depict the phenomenon they bring about.

This study therefore sought to review the extant theoretical and empirical literature with a view of identifying multidisciplinary linkages among all the constructs to address the existing gray areas and subsequently propose a 
theoretical model to address the emergent gaps in literature. The study's specific objectives were; to review the theoretical literature on the constructs; to review the empirical literature on the constructs; to identify the emerging theoretical and empirical gaps; and to propose a multidisciplinary theoretical model for responding to theoretical and empirical gaps. Through these objectives, the study enhances understanding of the constructs and how they are related.

In developing this paper, the authors respond to several calls for empirical and theoretical attempts in the field of strategic management. First, the paper addresses scholarly calls to extend managerial cognition research beyond content issue (Bogner \& Barr, 2000), integrating attention-based view with resource based view (Ocasio, 1997) and expounding managerial decision making under high velocity context (Kunc \& Morecroft, 2010). Further, an exploration of the direction strategic management is taking is attempted by borrowing relevant constructs from other disciplines. This directly addresses practical strategy formulation problems to employ resources in dynamic environments as well as contextual influence on decision making. The new theoretical model will form a foundation for knowledge advancement through theorizing and anchoring future empirical work from a broad point of view.

The methodology used by the researchers to achieve the stated objectives as well as attend to the various scholarly calls is that of a wide review of both theoretical and empirical literature relevant to the study to get a deeper understanding of the constructs. A conceptual assessment of the literature was conducted to give the researchers insights on how the constructs have been conceptualized by other scholars. A broad theoretical review was then done to provide theoretical anchorage for the constructs while the empirical review established the practical nature of the constructs in a way that enabled full appreciation of the character istics of the theories reviewed in research. The literature is presented under each construct and theory to which it relates and subsequently synthesized under issues arising at the end of literature and theoretical review sections.

\section{Literature Review}

\subsection{Conceptual Review}

The study is built on several constructs. This section presents a brief review of the relevant conceptual literature suitable provide an understanding of the nature and characteristics of each construct.

\subsubsection{Organizational Resources}

Organizational resources are assets possessed and controlled by firms, which also have the potential to generate competitive advantage for the organization that controls them (Wernerfelt, 1984; Barney, 2001). This competitive advantage is a predecessor of superior performance. These arguments are founded on the resource based view. Different scholars have characterized resources in different ways. Grant and Jordan (2012) viewed resources as assets or inputs (tangible or intangible) to production that an organization owns, controls or has access to on a semi-permanent basis. Daft (1983) on the other hand held that firm resources comprise of assets, capabilities, organizational processes, firm's attributes, information and knowledge controlled by a firm and which enable it to formulate and implement strategies that improve its efficiency and effectiveness. These scholars agree that resources are components of production but consensus is lacking as to what constitutes a resource.

Resources can be categorized in different ways. Juma (2014) for example categorized resources into tangible, intangible and human resources. Ismail et al. (2012) on the other hand categorized resources as either tangible or intangible resources. In the latter categorization, human resources were considered to be tangible resources. Barney (1991) regarded internal systems as an additional category of firm resources. Tangible resources are visible and thus easy to imitate while intangible resources are difficult to copy hence more valuable to a firm. Despite these differences in definition and categorization, resources have a unique relationship with competitive advantage which is a precursor of superior performance. Peteraf and Bergen (2003) posited that attainment of competitive advantage by firms largely derived from the characteristics of their resources and capabilities, which should be both valuable and costly-to-copy. Put differently, the resources must be valuable, rare, inimitable, and non-substitutable. These attributes are pointers to how heterogeneous and immobile a resource is and hence how important it is to the firm in generating sustained competitive advantage. A different perspective is introduced by considering capabilities which Amit and Schoemaker (1993) defined as the firm's capacity to deploy resources to produce a desired effect. Thus, it is the presence of the capabilities that makes it possible to utilize resources rather than possessing resources itself. Some scholars have also considered capabilities as a resource (Akio, 2005). When considered as such, capabilities become the most critical as they facilitate reconfiguration of current resources for future competitiveness hence firms with similar resources may experience different performance. 
Barney (2001) however argued that not all resources are strategically relevant. Some may inhibit conception of and implementation of valuable strategies, others may lead to implementation of strategies that diminish efficiency and effectiveness while others do not influence firm's strategizing processes. The Resource based approach that has offered the theoretical anchorage the understanding of resources has been criticized for excluding the effects of the external environment with scholars calling for an integrated model in recognition of the profound role played by external environment in firm competitiveness. Realization of such a model will make firms more responsive to external demands.

\subsubsection{Industry Velocity}

The construct of industry velocity is a characteristic of the organizational environment. Scholars have described organizational environment in different ways. Frishammar (2006) for example described organizational environment using five concepts; task environment, domain, territory, sub-environment and industry. Pfeffer and Salancik (1978) on the other hand divided the environment into three levels; one comprising of organizations which are associated to each other, another made up of organizations with direct interaction and a third level which is the enacted environment. The last level is the one that is perceived and therefore what influences strategic actions. Notably, due to differences in perception these levels inevitably overlap.

This perceived environment and the dynamism thereof proxies the industry velocity. Industry velocity may be described as either low or high depending on the level of dynamism. The general distinguishing factors of dynamism in the above two cases are changes in demand, competition, technology and/or regulation (Bourgeis \& Eisenhardt, 1988). Stability of growth rates, frequency of entry and exit of firms in and out of the industry as well as ease of sustaining competitive positions are also key factors in defining the level of dynamism and consequently the industry velocity. Although demarcation between low and high industry velocity is largely a relative phenomenon, Ansoff (1979) suggested a model for assessing variability in business environment. The model comprises of five turbulence levels ranging from placid and predictable to highly changeable and unpredictable. In increasing order of dynamism, the five levels are repetitive, expanding, changing, discontinuous and surprising.

Thus, the high velocity industry context is characterized by significantly surprising changes described by unpredictability of changes in the firm environment. The changes are further described by rate, turbulence and magnitude (Nadkarni \& Narayanan, 2007). Rate represents regularity of changes, turbulence the unpredictability of the changes while magnitude involves the size of changes. Whether the changes are objective phenomenal or a cognitive creation of managers remains debatable.

Despite the foregoing debate, scholars have advanced contradicting arguments on the role of external environment dynamism in formulating strategies to apply firm resources and subsequent performance. Some scholars have insisted that the external environment does not influence firm performance (Cool \& Schendel, 1988; Akio, 2005). Juma (2014) on the contrary argued that organizations need more than just possessing resources but require to constantly re-combine them as the external environment changes. This arises from the fact that industry structures and boundaries are becoming more diffuse, are far from stable and are undergoing frequent transition. Consequently, organizations that adapt quickly as environmental dynamism peaks are likely to be more successful than those slow to respond to environmental cues. Hart (1995) broadened examination of environmental dynamism by advocating for consideration of the repercussions the physical environment rather than the business environment has on business operations.

Consequently, for resource based view to remain relevant, it must embrace and internalize the tremendous challenges created by the natural environment. Further, Meyer, Estrin, Bhaumik and Peng (2009) called for infusion of resource based view and institutional theory which is externally oriented for strong explanatory and predictive power of the former. Kilika (2012) advocated for effective change management in dynamic environments by elevating the role of human resource development in the growth and development of human resources as the agents of change.

From these issues, it is evident that dynamism in the firm environment presents enormous challenges in formulating effective strategies which Bogner and Barr (2000) contend have not been widely studied. Firm-environment interaction also has ramifications on the amount of information available to managers hence necessity of a cognitive coping mechanism. To effectively perceive and interpret the enormous amounts of environmental information, managers resort to attention focus.

\subsubsection{Attention Focus}

Attention focus arose as a deviation from the theories of rational choice following recognition of the limitations 
of human rationality in giving meaning to how decisions were made by firms (Ocasio, 1997). It is a key cognitive mechanism to assist managers make decision in high industry velocity context characterized by information overload. Huczynski and Buchanan (2013) argued that managers' rely on attention focus to selectively attend to certain environmental aspects which eventually affects strategic decision making. This makes firms' environment a subjective phenomenon with different managers perceiving the same environment differently. What attracts the decision makers' attention are those aspects that are most salient. These are the novel ones in context, those which diverge from expectations or are relevant to the objectives of the firm (Fiske \& Taylor, 1991).

Nadkarni and Barr (2008) argued that organizations do not respond to environmental changes in their raw form unless they notice the variations and interpret how they affect their firm. Thus, it is not the total changes in the environment that influence resources-performance relationship but rather the portion of these changes that is perceived. These subjective representations of the environment developed by strategic decision makers are narrow in nature (Nadkarni \& Barr, 2008) a phenomenon that Bogner and Barr (2000) attribute to cognitive limits which preclude top managers from developing a wholesome understanding of their environments. Simon (1979) in advancing this theme introduced a behavioral logic based on bounded rational decision making model. He noted that environmental factors limited decision making to those ones that are good enough for the situation through sequential evaluation of alternatives. These views raise a serious concern whether attention focus leads to application of resources to less than ideal environmental demands (Huczynski \& Buchanan, 2013). Another concern is whether comprehensiveness of decision making is compromised by the narrow perspective of the environment. Despite the shortcomings, a cognitive approach to explain how firms interpret their environment to inform effective application of resources for attainment of superior performance is fundamental in strategic management research.

\subsubsection{Firm Performance}

Juma (2014) argued that firms are in various ventures to succeed hence superior performance is crucial to organizations. Muchemi (2014) described organizational performance as efficiency and effectiveness in usage of resources accompanied by the accomplishment of set goals. Firm performance has been widely used in strategic management as the dependent variable (Juma, 2014) but debates as to the sources of high performance prevail. Rose and Thomasen (2009) associated it to reputation, Barney (2007) attributed it to organizational culture, Barney and Hesterly (2010) attributed it to intangible resources while Nevo and Wade (2010) argued that it was not based on a single resource.

Whichever the source, application of current resources does not assure sustainability of high performance. Environmental dynamism in high velocity industry context demands that the resources be continuously modified (Helfat, Finkelstein, Mitchell, Peteraf, Singh, Teece \& Winter, 2009) in order to cope with the future. This ability is what is referred to as dynamic capability. Thus, resources lead to capabilities which lead to sustainable competitive advantage which in turn leads to sustainable superior performance. However, Rose et al. (2010) posited that competitive advantage is a relational concept and it is also context-specific. Thus, it may sometimes not result in superior performance and sometimes superior performance may be achieved without competitive advantage hence need for firms to monitor their performance to correct ineffective strategies.

However, scholars have not reached consensus on how best to monitor and measure performance. Nevertheless, financial measures remain the most commonly used methods (Muchemi, 2014). These approaches have however been criticized for their narrow view of performance and largely satisfying the private sector which is rarely interested in non-financial performance indicators while increased environmental dynamism further calls for broader approaches that consider both internal and external stakeholders (Kaplan \& Norton, 1992). Kontoghiorghes, Awbrey and Feurig (2005) in contributing to performance measurement argued that learning should be considered as it is a key element in developing and maintaining competitive advantage a view amplified by Kilika (2012) who held that learning was a major contributor to organizational performance. The Balance Score Card and Tripple Bottom Line approaches have been advanced to answer these calls for broader approaches. Firms however continue to grapple with challenges of quantifying non-financial performance.

\subsubsection{Issues Arising from the Conceptual Discussion}

From the conceptual review, an enhanced understanding of the constructs of organizational resources, industry velocity, attention focus and firm performance has been realized. Scholars have also suggested possible relationships among the constructs. The potential of organizational resources has been subordinated to context which demands that the resources be regularly reconfigured. The psychological process of attention focus in helping firms deal with information mutation has also been brought out. The scholars have further made efforts 
to describe the constructs of interest and also suggested indicators suitable to operationalize them. For example, indicators of organizational resources have been brought out as tangible resources, intangible resources, human resources and internal systems (Juma, 2014; Ismail et al., 2012; Barney, 1991). While reflecting on environmental dynamism, indicators for industry velocity have been suggested as being rate, turbulence and magnitude of changes (Nadkarni \& Narayanan, 2007). Those on attention focus have been identified as attentional perspective, attentional engagement and attentional selection (Ocasio, 2011). Indicators of firm performance have been broadly classified into financial and non-financial (Muchemi, 2014). Over and above these, researchers have introduced the construct of capabilities as a pathway through which resources lead to superior and sustained performance (Rose et al., 2012). This is in recognition of the role that capabilities play in enabling firms to exploit resources.

The literature has also demonstrated areas of consensus as well as divergence among researchers. Consensus has been shown in regard to value of resources as a major contributor to firm performance, inherent instability of high velocity industry contexts and organizations' ultimate goal of superior performance. Conversely, scholarly incoherence has been shown to exist with respect to endurance of resource based competitive advantages, role of the environment in strategy formulation, the nature of the environment as an objective phenomenon or otherwise and measurement of performance. Different views are presented each of which can qualify as a different school of thought in strategic management.

Further, to fully establish the practical nature of the constructs, several empirical attempts have been made with the constructs playing different roles. For example, Čater and Čater (2009) linked (in)tangible resources to company's competitive advantage and performance; Gruber, Heineman and Hungeling (2010) explored how resources and capabilities related to performance; Ting, Wang and Wang (2012) examined how innovation strategy influenced performance when moderated by environmental dynamism; Alon, Jiao, Kwong and Cui (2013) studied how the relationship between dynamic capabilities strategy and new venture performance was moderating by environmental dynamism; Nadkarni and Barr (2008) assessed the role of managerial cognition in influencing strategic action; Morgan, Vorhies and Mason (2009) examined how market orientation and marketing capabilities influenced firm performance; while Rose et al. (2010) linked organizational resources to firm performance as mediated by competitive advantage.

However, despite the attempts by scholars to describe the constructs, the theoretical grounding is lacking in these descriptions hence a call to consider a theoretical underpinning of the constructs. This is helpful in comparing new knowledge to existing theoretical models to provide direction on how the constructs would apply to different contexts. In reflecting on the different researches, scholars suggest the need for a wide range of theories for full conceptualization and theorizing of the relationships among the constructs of the study. Thus, the phenomenon of organizational resources and firm performance in high velocity industry context as impacted by managerial cognition derives from several theories which also form the basis for developing a theoretical framework.

\subsection{Theoretical Review}

The above conceptual review has not presented theoretical anchorage for constructs in this study. The constructs thus require a theoretical underpinning which is derived from a variety of theories. These are the resource based view, dynamic capabilities view, organizational learning theory, resource dependence theory, open systems theory, contingency management theory and the attention based view.

\subsubsection{Resource Based Theory}

The resource based view originated from the work of Penrose (1959), who argued that the resources owned, deployed and used by the organization are more significant than industry structure. The theory is thus inward rather than outward looking by elevating organizational resources as the single requirement for high firm performance. The resource based view advances two key postulates, that of resource heterogeneity and another of resource immobility. Heterogeneity of resources makes firms unique with regard to the resources that they own and control (Barney, 1991). Resource immobility on the other hand assumes that resources are relatively stable among firms such that heterogeneity can be lasting (Selznick, 1957). Over the years, the resource based view has emerged distinctly as one of the more outstanding paradigms for understanding organizational activities and their competitive strategies with contributions from such scholars like Barney (1991 \& 2001) and Peteraf and Barney (2003).

According to the resource based view, if a firm is to achieve competitive advantage, it must obtain and control valuable, rare, inimitable, and non-substitutable (VRIN) resources and capabilities, and in addition have the organization in place that can absorb and apply them (Barney, 2001). Thus, the theory's contribution to the study 
is in anchoring the constructs of organizational resources and firm performance. The theory suggests that organizational resources contribute to superior firm performance.

\subsubsection{The Dynamic Capabilities View}

The dynamic capabilities view advanced by Teece, Pisano and Shuen (1999) seeks to extend the resource based view which largely focuses on the present value of resources. It holds that resources are not directly linked to superior performance and argues that capabilities are the source of competitive advantage while resources are the source of capabilities (Grant, 1991). Ambrosini and Bowman (2009) held that dynamic capabilities view extends the resource based view argument by addressing how valuable, rare, difficult to imitate and imperfectly substitutable resources can be created and how the current stock of valuable resources can be refreshed as the environment changes. It thus thrives on the fact that dynamic environments quickly erode the value of current resource stock thus requiring regular renewal. Dynamic capabilities thus allow firms to have sustained competitive advantage (Leonard-Barton, 1992).

The dynamic capabilities view contributes to this study by extending the resource based view and recognizing the construct of industry velocity as a strong influencer of resources- performance interaction. It helps in drawing of conclusions on how firms choose selected resources and reconfigure them to continuously address changing environment. It also introduces capabilities as a new construct for consideration in the study and suggests that organizational resources influence firm performance through the capabilities as opposed to direct relationship.

\subsubsection{Organizational Learning Theory}

Organizational learning theory reflects a collection of several sub-theories with a similar theme and is central in explaining how firms and human beings, their most valuable resource, acquire knowledge. Among the classical learning theories include experiential learning theory (Kolb, 1984), adaptive and generative learning theory (Senge, 1990) and assimilation theory (Nevis, DiBella, \& Goulds, 1995). Owing to its nature of intangibility and difficulty to imitate, knowledge has been advanced as one of the most valuable organizational resources. Curado (2006) posited that knowledge accumulated through organizational learning, leading to superior knowledge bases, can be associated with high performances at organizational level. Spender and Grant (1996) on the other hand held that continuous learning in an organization guarantees that employees are up-to-date in terms of knowledge and information, thus strengthening human capital at large

Organizational learning theory contributes to this study by providing a theoretical foundation for human resources and attention focus. It argues that human resources should be developed as they are considered the most valuable asset within a firm. It also hints at the importance of cognitive processes by recognizing that the environment is largely a mental phenomenon rather than an objective construct. The construct of attention focus derives from this theory on the basis of reliance on environmental cues learnt from the past to minimize time for decision making.

\subsubsection{Resource Dependence Theory}

Resource dependence theory has its origins in the work of Pfeffer and Salancik (1978). It describes how external resources of organizations influence organizational behavior. It also explains how strategic managers make decisions in an environment that gives power to the firms but at the same time controls access to the resources (Huczynski \& Buchanan, 2013). Firms must therefore seek to minimize reliance on their environment as a means of maintaining control over critical resources and reducing uncertainty especially in highly dynamic environments. Huczynski and Buchanan, (2013) argued that only the most critical and scarce resources are focused on and therefore support the need of decision makers' selective cognitive behavior.

The theory which is externally oriented complements the internally focused resource based view. It alludes to the selective behavior of managers by emphasizing that firms should seek to have the most critical and most scarce only. It thus anchors the construct of industry velocity by suggesting that the construct has influence on resource performance relationship.

\subsubsection{Open Systems Theory}

Open systems theory arose after World War II as a reaction to previous theories of organizations which had treated organizations as closed systems (Bastedo, 2004). The theory postulates that organizations are strongly influenced by their environment which affects the strategies that they formulate. The environment acts as a source of strategic resources that are vital for organizational sustenance, survival and superior performance. The theory thus recognizes the importance of organizational environment and the power it has to influence strategic behavior especially in high velocity industry context. It supports the dynamic capabilities view criticism of the resource based view by emphasizing the role of external environment. The theory also complements the resource 
dependence theory in its external orientation. It thus anchors the construct of industry velocity and its contingent role.

\subsubsection{Contingency Management Theory}

The contingency management theory proposed by Fiedler and Garcia (1987) argues that organizational strategic actions depend on the contingencies of the situation. Islam and $\mathrm{Hu}(2012)$ argued that contingency theory is an approach to organizational behavior offering explanations as to how contingent factors influence the design and function of organizations. Van de Ven and Drazin (1985) postulated that organizational outcomes are the consequences of a fit between a number of factors. However, there is no a best way to achieve the fit which calls for continuous and powerful evaluation of contingent factors to inform strategy formulation. The strategies so formulated should also be flexible enough to readily adapt to rapidly changing context.

This theory holds that strategic decisions are made to fit a constantly dynamic environment. It is this fit that determines the ultimate firm performance. The theory is thus aligned to the purpose of the dynamic capabilities view in seeking to reconfigure organizational resources to fit specific environmental demands. It also augments the open systems theory proposition on firm environment interaction. It anchors the constructs of industry velocity and firm performance.

\subsubsection{Attention Based View}

Attention based view was advanced by Ocasio (1997) in furtherance of understanding of how firms behaved within their operating environments. The theory is based on recognition of limitations of human cognitive capacity in explaining how firms arrive at strategic decisions and as a consequence it is founded on their bounded capacity to be rational. It is based on the premises of focus of attention, situated attention and structural distribution of attention. Attention based view follows Weick's (1979) work on attention emphasizing selective attendance to the environment stimuli. This was in recognition that a firm's environment is complex and thus organizations are bounded in their ability to attend to every (or even most) environmental stimuli. Consequently, strategists selectively attend to a limited set of stimuli, while ignoring others.

Thus, attention based view through recognition of cognitive limitations by decision makers especially in highly dynamic environment provide a theoretical perspective for use of attention focus mechanism to filter out the non-fundamental aspects of the environment. The theory thus helps explain that only a portion of the environment is attended to during strategic decision making process.

The theoretical review has revealed existence of diverse theories that have contribution to this study. The theories give a broad perspective to the understanding of strategic management. From the theories, a number of constructs relevant to the study namely organizational resources, capabilities, firm performance, industry velocity and attention focus have been identified. The theories have also provided possible indicators to the constructs.

\subsubsection{Issues Arising from the Theoretical Discussion}

The theories reviewed are of phenomenal application to this study as they properly anchor the indicators of the constructs of interest. For example, firm assets and competitive advantage are identifiable in the resource based view, dynamic capabilities view, organizational learning theory and resource dependence theory. Environmental influence is identifiable in resource dependence theory, open systems theory and contingency management theory. Attention awareness, focus and selective perception can be identified in attention based view.

Propositions by the theories present areas of convergence in their views of various constructs and the phenomena they bring forth in strategic management. Areas of likely complementarity can also be identified which highlight an opportunity for theorizing in strategic management and empirical work. For example, in considering the resource based view and dynamic capabilities view, complementarities are found in the latter seeking to extend the former through recognition of environmental influence. Complementarity also exists between the resource based view and the resource dependence theory with the former focusing on the internal environment while the latter focuses on the external environment. Reinforcement among the theories is also visible. For example in considering the postulates of resource dependence theory, open systems theory and contingency management theory, reinforcement exists in their emphasis on external environment in strategic decision making.

To appreciate the full practical character of the theories in research, they have been used in a variety of empirical studies to offer theoretical underpinning for different constructs. For instance, Liang, You and Liu (2010) used resource based view to anchor the constructs of resources and firm performance mediated by organizational capabilities; Juma (2014) used resource based view and dynamic capabilities view in anchoring organizational resources and performance moderated by corporate governance; Ndofor, Sirmon and He (2011) applied resource 
based view and competitive dynamics theory to anchor firm resources and performance mediated by competitive actions; Njoroge (2015) used resource based view and organizational learning theory in anchoring organizational resources and performance mediated by competitive advantage; Ocasio (2011) used attention based view alongside other theories to underpin attention and organizational adaptation; while Su, Xie, Wang and Li (2011) used resource based view and dynamic capabilities view in their study on entrepreneurial strategy making and performance as moderated by organizational resources. In considering the empirical studies reviewed, none of the researchers used resource dependence theory, open systems theory and contingency management theory. However, in reflecting on the postulates of these theories, it is evident that they can augment those found in the reviewed empirical studies to provide a richer theoretical anchorage of the constructs of this study.

The theories reviewed also suggest possible linkages among constructs of interest useful to guide building theoretical models. For example, the resource based view supports a linkage between organizational resources and firm performance which is refined by the dynamic capabilities view by emphasizing necessity for permissive capabilities. Resource dependence theory, open systems theory and contingency management theory suggest external environment influence on the direct relationship between organizational resources and firm performance. Attention based view suggests that only a portion rather than the entire environment influences this direct relationship. However from the theoretical review, no single theory was found to be sufficient in explaining the phenomenon of organizational resources and firm performance as influenced by interaction between context and managerial psychological processes. This study therefore advocates for a single theory to adequately address this gap and further guide future empirical research in strategic management.

\section{The Call for a Theoretical Framework}

This paper sought to describe the constructs of organizational resources, industry velocity, attention focus and firm performance from a multidisciplinary perspective and identify linkages among them in high velocity industry context by reviewing extant literature. In considering this literature to understand the constructs and provide theoretical grounding, conceptual, theoretical and empirical gaps have emerged as off-shoots of scholarly discussions.

Notable is the incoherence with respect to endurance of resource based competitive advantages, role of the environment in strategy formulation, the nature of the environment as an objective phenomenon or otherwise and measurement of performance still exists. Discussions regarding resource-performance relationship have clustered around two phenomena, with some scholars arguing that resources are a necessary and sufficient condition for superior performance while others see the relationship as context defined. Closely related to this, two camps seem to emerge concerning whether the external environment needs to be considered during strategy formulation or not. Similarly, two opposing views stand out regarding the nature of the external environment with an argument that the environment is an objective phenomenon while a counter argument regards the environment as a highly subjective phenomenon defined by managerial cognitive mechanisms. Lastly, how broadly firm performance should be measured is also clustered around two viewpoints with some scholars sticking to the traditional and narrower financial measurement approaches while others are calling for broader approaches.

Conceptually, none of the reviewed studies brought all the constructs of this study together in a single study. Different scholars conceptualized the relationships between constructs in diverse ways. It is therefore necessary to develop a robust model that integrates all the constructs together. Theoretically, no single theory was found to ground all the suggested relationships. However taken together, the theories presented areas of complementarity and reinforcement hence potential for theorizing. A theoretical model may provide a firm base for springing and crystallizing a single new theory. Empirically, scholars have not unanimously typified organizational resource in terms of their significance to firm performance. There is also no common standing among scholars on the application of attention focus and approach for measuring firm performance. A new theoretical model will contribute to these gray areas by suggesting possible categorization of resources, define applicability of the construct of attention focus in high velocity industry context and contribute to literature on firm performance measurement.

As more research is conducted and new findings discovered, the scholarly future may require constructs initially treated as unrelated to be brought together in a single study. There may be need to borrow certain constructs from other disciplines to fulfill strategic management objectives. This study by proposing a new theoretical model takes this step by borrowing the construct of attention focus from organizational behavior and integrating it into a traditional strategic management model featuring organizational resources and firm performance. The new theoretical model also reflects evolving nature of knowledge requiring closer scrutiny of constructs and how they relate and will form the basis for anchoring future empirical studies. 
Need for a theoretical model is also informed by its central role in advancing knowledge. Mutanen (2015) argued that the goal of any scientific inquiry is to gain new knowledge. However, to be a reliable way of advancing knowledge, such an inquiry must be systematic institutionally and theoretically. Institutional systematicity encompasses organizations like universities or those dedicated to research. Conversely, theoretical systematicity describes organization of knowledge into theories and in a methodological way (Mutanen, 2015). In a similar vein, using the various debates touching on the role of theory in advancement of scientific knowlegde, Wandiga, Kilika and James (2017) justified a case for development of new theoretical models to precede empirical work based on an epistemological perspective. Thus, to make scientific knowledge more than mere compilation of distinct pieces of information, its formulation should ideally be in the form of a theory in a strict logical sense. This is a direct call for theoretical models to organize new knowledge. From the foregoing, this study proposes a theoretical model for guiding future empirical studies in strategic management.

\subsection{The Proposed Theoretical Model}

Based on the discussions made in this paper, several constructs emerge from both the theoretical and conceptual literature. These constructs are organizational resources, firm capabilities, industry velocity, attention focus and firm performance. In reflecting on the role of a theory to explain, predict and understand phenomena and also advance knowledge in a predictable way, the authors propose the following theory designating different roles in a phenomenon that involves the above five constructs. The model presents a phenomenon whose antecedent factor is organizational resources. Organizational resources are operationalized using four dimensions; tangible resources, intangible resources, human resources and internal systems. The intermediate factor emerging from organizational resources is firm capabilities with the dimensions of sustenance of competitive advantage and value creating strategies. The contingent factor is presented by an interaction of the constructs of industry velocity and attention focus. Industry velocity has three dimensions; rate of industry change, turbulence of changes and magnitude of changes while those of attention focus are attentional perspective, attentional engagement and attentional attention. The ultimate factor on the other hand has been operationalized through financial and non-financial indicators.
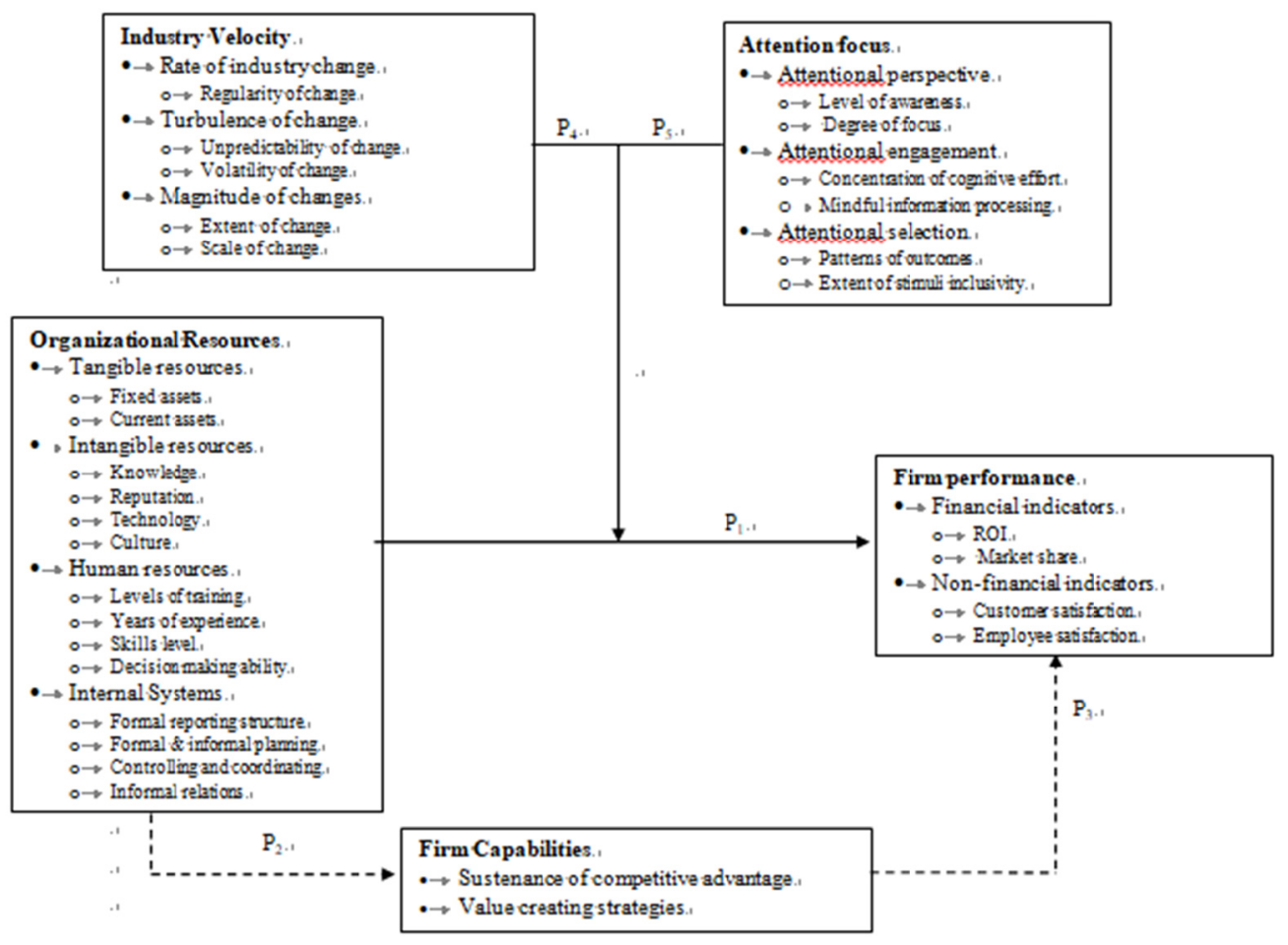

Figure 1. Theoretical framework linking organizational resources, industry velocity, attention focus and firm performance as mediated by firm capabilities

Source: Authors (2018). 


\subsection{Propositions}

\subsubsection{Organizational Resources and Firm Performance}

The construct of organizational resources has been advanced as a focal point in the performance of a firm and in strategic management in general. This contribution has been studied since the resource based paradigm was proposed. The dimensions used to operationalise the construct have various indicators. Indicators for tangible resources are fixed and current assets. They have a physical form and are therefore easy to acquire or imitate. Consequently, their value as a source of sustainable competitive advantage is limited as competitors can acquire them in the long run. They are nevertheless important as they provide a basis on which the other resources are exploited.

Intangible resources indicators consist of knowledge, reputation, technology and culture. Unlike tangible resources, they do not have a physical form and therefore they are not easy to imitate. Further, the complexity with which they combine with the tangible and human resources makes competitors unable to apply them effectively even if they manage to acquire them. They are thus considered to have more value as sources of sustainable competitive advantage hence sustainable superior performance. Human resources indicators on the other hand comprise of level of training, years of experience, skills level and decision making ability. Human resources are a special category of resources as they control all the other resources. They also harbor several intangible resources the most key being tacit knowledge though they are themselves mobile through job change. Internal systems are institutional-wide and provide synergy among the other resources. Their indicators comprise of organizational formal reporting structure, its formal and informal planning, controlling and coordinating mechanisms and informal relations within and without the organization. The indicators of the financial dimension of firm performance are ROI and market share while those of the non-financial dimension are customer satisfaction and employee satisfaction. The available theoretical and empirical literature proposes a relationship between deployment organizational resources and firm performance. Specifically, the resource based view suggests that firms operating in high velocity industry contexts should acquire and control relevant resources to guarantee superior performance. Thus, the paper proposes that:

Proposition 1: Firms in high velocity industry contexts that acquire and control relevant organizational resources aligned to the context will realize high level of performance.

\subsubsection{The Role of Firm Capabilities}

High velocity industry context is characterized by high levels of environmental dynamism which makes competitive advantages premised on organizational resources short lived and easy to erode. In such cases, the path from resources to performance is not direct but goes through an intermediate state for the resources to unleash their potential. This intermediate state describes the capabilities that firms must build to align the resources to address the demands of the high velocity context. The capabilities present the ability of organizations to renew resources over time to respond to changing contexts. Further, even though deployment of resources is argued to lead to superior firm performance, the manner in which the resources are exploited is contingent upon the existing firm capabilities. The strength of organizational resources can thus be argued to be domiciled in the firm's capabilities. It is these capabilities that enable firms to sustainably exploit organizational resources and generate sustainable competitive advantage hence lasting superior performance and are founded on sustainable value creating strategies. Thus, the paper proposes that:

Proposition 2: Firms in high velocity industry contexts that are conscious about the demands of their external contexts will build relevant firm capabilities to properly align organizational resources to changing environmental demands.

Proposition 3: Even though the configured resources in high velocity industry contexts have been proposed to influence performance, the strength of such influence is dependent on the state of capabilities derived from the resources deployed by firms in high velocity industry contexts.

\subsubsection{The Joint Contingent Effect of the Interaction between Industry Velocity and Attention Focus}

Industry velocity describes the nature of the industry in which the firms operate and is characterized by rate, turbulence and magnitude of change. Rate refers to the regularity of changes, turbulence to the unpredictability of these changes while magnitude represents the size of changes. High velocity industry context is characterized by frequent environment changes, with the changes being highly unpredictable and big in magnitude. Since organizations do not operate in isolation and their boundaries are characteristically porous, the organizations' strategy formulation process is inevitably influenced by these external environmental variations. The strategies 
formulated and implemented therefore seek to address these contextual factors. Particularly, firms have to contend with a peculiar nature of competition and performance in these environments which is characterized by competence-destroying change and the limited ability of managers to foresee the nature of these changes (Bogner \& Barr, 2000). This is due to the massive amounts of information arising from the changes often in amounts greater than the cognitive abilities of decision makers to perceive and interpret it. It is thus in high velocity industry context that the value of attention focus described as the extent to which top managers' subjective representations of their external environment are dominated by concepts related to one (or more) domain over others is founded. The necessity of attention focus arises as managerial teams attempt to shield themselves from information overload in high velocity industry contexts by focusing only on aspects of the environment which they deem critical to inform strategy formulation. In this way, the interaction between industry velocity and attention focus allows only some environmental stimuli to be considered and factored in the frame of reference when making strategic decisions in organizations. Thus, the paper proposes that:

Proposition 4: Even though deployment of resources by firms in high velocity contexts is likely to influence their performance, the contribution of the resources to such performance is contingent upon the state of industry velocity experienced by the firm.

Proposition 5: Even though deployment of resources by firms in high velocity contexts is likely to influence their performance, the contribution of the resources to such performance is contingent upon the external environmental stimuli that the decision makers have selectively attended to and focused on.

\section{Conclusions and Direction for Future Research}

This theoretical paper was aimed at reviewing extant conceptual, theoretical and empirical literature to identify gaps in the relationships among the constructs of organizational resources, industry velocity, attention focus and firm performance. The paper further aimed at suggesting a theoretical model based on a multidisciplinary approach and propose propositions to fill the identified gaps. The reviewed literature showed varied linkages among resources, industry velocity, attention focus and firm performance. The literature also identified an additional construct that influences these interactions. It showed that organizational resources are not directly related to firm performance but instead firm capabilities are intermediate factors and that they define the mechanism through which resources affect firm performance.

This paper therefore extends the level of understanding in the extant literature on organizational resources, industry velocity, attention focus and firm performance and also makes suggestions for future research. The paper has identified gaps in extant empirical literature and provided an integrated and more inclusive approach for improving visualization and understanding of the relationships among the constructs of organizational resources, industry velocity, attention focus and firm performance by inviting the construct of firm capabilities into the interactions. New propositions have as a consequence been put forward to enrich the extant literature on organizational resources, industry velocity, attention focus and firm performance interactions and further to cement arguments on how the additional construct of firm capabilities influence the relationships and affect firm performance. From the study, it is evident that the future of strategic management research lies in multidisciplinary approaches to strategic problems. Strategic managers and scholars should therefore integrate other disciplines to address strategic management gaps. Further, the proposed theoretical framework should be practically tested in guiding future empirical research in high velocity industries in diverse sectors. These industries include the computer industry, airlines industry, insurance industry, informational industry, retail banking, fast food businesses, health care industry and real estate among others. These are the industries characterized by frequent, unpredictable and enormous changes in demand, competition, technology and/or regulation signifying high environmental variability.

\section{References}

Akio, T. (2005). The Critical Assessment of the Resource-Based View of Strategic Management. Ritsumeikan International Affairs, 3, 125-150.

Alon, I., Jiao, H., Kwong, K. C., \& Cui, Y. (2013). The moderating effects of environmental dynamism on the relationship between dynamic capabilities strategy and new venture performance in an emerging market. Journal of Engineering and Technology Management, 30(2), 188-205. http://doi.org/10.1016/j.jengtecman.2013.01.005

Ambrosini, V., \& Bowman, C. (2009). What are dynamic capabilities and are they a useful construct in strategic management? International Journal of Management Reviews, 11(1), 29-49. http://doi.org/10.1111/j.1468-2370.2008.00251.x 
Amit, R., \& Schoemaker, P. J. (1993). Strategic assets and organizational rent. Strategic Management Journal, 14(1), 33-46. http://doi.org/10.1002/smj.4250140105

Ansoff, H. I. (1979). Model of environmental turbulence in strategic management. London: Palgrave Macmillan. http://doi.org/10.1007/978-1-349-02971-6_5

Barney, J. (1991). Firm resources and sustained competitive advantage. Journal of Management, 17(1), 99-120. http://doi.org/10.1177/014920639101700108

Barney, J. B. (2001). Is the resource-based "view" a useful perspective for strategic management research? Yes. Academy of Management Review, 26(1), 41-56. http://doi.org/10.2307/259393

Barney, J. B. (2007). Gaining and sustaining competitive advantage. Upper Saddle River, New Jersey: Pearson Prentice Hall.

Barney, J. B., \& Hesterly, W. S. (2010). Strategic management and competitive advantage concept. Upper Saddle River, New Jersey: Pearson Prentice Hall.

Bastedo, M. N. (2004). Open systems theory. University of Michigan. SAGE. http://doi.org/10.4135/9781412939584.n406

Bogner, W. C., \& Barr, P. S. (2000). Making sense in hypercompetitive environments: A cognitive explanation for the persistence of high velocity competition. Organization Science, 11(2), 212-226. http://doi.org/10.1287/orsc.11.2.212.12511

Bourgeois III, L. J., \& Eisenhardt, K. M. (1988). Strategic decision processes in high velocity environments: Four cases in the microcomputer industry. Management Science, 34(7), 816-835. http://doi.org/10.1287/mnsc.34.7.816

Čater, T., \& Čater, B. (2009). (In) tangible resources as antecedents of a company's competitive advantage and performance. Journal for East European Management Studies, 186-209.

Cho, T. S., \& Hambrick, D. C. (2006). Attention as the mediator between top management team characteristics and strategic change: The case of airline deregulation. Organization Science, 17(4), 453-469. http://doi.org/10.1287/orsc.1060.0192

Cool, K., \& Schendel, D. (1988). Performance differences among strategic group members. Strategic Management Journal, 9(3), 207-223. http://doi.org/10.1002/smj.4250090302

Curado, C. (2006). Organisational learning and organisational design. The learning organization, 13(1), 25-48. http://doi.org/10.1108/09696470610639112

Daft, R. (1983). Organization theory and design. New York: West Publishing.

Ensley, M. D., Pearce, C. L., \& Hmieleski, K. M. (2006). The moderating effect of environmental dynamism on the relationship between entrepreneur leadership behavior and new venture performance. Journal of Business Venturing, 21(2), 243-263. http://doi.org/10.1016/j.jbusvent.2005.04.006

Fiedler, F. E., \& Garcia, J. E. (1997). New approaches to leadership, cognitive resources and organizational performance. New York: John Wiley and Sons.

Fiske, S. T., \& Taylor, S. E. (1991). Social cognition. New York: McGraw-Hill.

Frishammar, J. (2006). Organizational environment revisited: a conceptual review and integration. International Studies of Management \& Organization, 36(3), 22-49. http://doi.org/10.2753/imo0020-8825360302

Goeltz, D. R. (2014). Alliance portfolio characteristics and firm performance. Journal of management and marketing research, 16, 1.

Grant, R. M. (1991). The resource-based theory of competitive advantage: Implications for strategy formation. California management review, 33(3), 114-35. http://doi.org/10.2307/41166664

Grant, R. M., \& Jordan, J. (2012). Foundations of strategy. London: John Wiley \& Sons Ltd.

Gruber, M., Heinemann, F., Brettel, M., \& Hungeling, S. (2010). Configurations of resources and capabilities and their performance implications: an exploratory study on technology ventures. Strategic Management Journal, 31(12), 1337-1356. http://doi.org/10.1002/smj.865

Hamel, G., \& Prahalad, C. K. (1994). Competing for the future. Boston: Harvard School Press.

Hart, S. L. (1995). A natural-resource-based view of the firm. Academy of Management Review, 20(4), 986-1014. http://doi.org/10.2307/258963 
Helfat, C. E., Finkelstein, S., Mitchell, W., Peteraf, M., Singh, H., Teece, D., \& Winter, S. G. (2009). Dynamic capabilities: Understanding strategic change in organizations. John Wiley \& Sons.

Hitt, M. A., \& Tyler, B. B. (1991). Strategic decision models: Integrating different perspectives. Strategic Management Journal, 12(5), 327-351. http://doi.org/10.1002/smj.4250120502

Huczynski, A. A., \& Buchanan, D. A. (2013). Organizational behavior. Edinburgh Gate: Pearson Education Ltd.

Islam, J., \& Hu, H. (2012). A review of literature on contingency theory in managerial accounting. African journal of Business Management, 6(15), 5159. http://doi.org/10.5897/ajbm11.2764

Ismail, A. I., Rose, R. C., Uli, J., \& Abdullah, H. (2012). The relationship between organizational resources, capabilities, systems and competitive advantage. Asian academy of Management Journal, 17(1).

Juma, O. W. (2014). Organizational resources, corporate governance structures and performance of Kenyan state corporations. Unpublished MBA Thesis.

Kaplan, R. S., \& Norton, D. P. (1992). The Balanced Scorecard-Measures that Drive Performance. Harvard Business Review, 70(1).

Kilika, J. M. (2012). Institutional context, collaboration, human resource development infrastructure and performance of universities in Kenya. Unpublished Ph. D Thesis. School of Business, University of Nairobi.

Kolb, D. (1984). Experiential learning: Experience as the source of learning and development. New Jersey: Prentice Hall.

Kontoghiorghes, C., Awbre, S. M., \& Feurig, P. L. (2005). Examining the relationship between learning organization characteristics and change adaptation, innovation, and organizational performance. Human Resource Development Quarterly, 16(2), 185-212. http://doi.org/10.1002/hrdq.1133

Kraaijenbrink, J., Spender, J. C., \& Groen, A. (2009). The resource-based view: A review and assessment of its critiques. Journal of Management, 36(1), 349-372. http://doi.org/10.1177/0149206309350775

Kunc, M. H., \& Morecroft, J. D. (2010). Managerial decision making and firm performance under a resource-based paradigm. Strategic Management Journal, 31(11), 1164-1182. http://doi.org/10.1002/smj.858

Learned, E. P., Christensen, C. R., Andrews, K. R., \& Guth, W. P. (1965). Business policy: Text and cases. IL: Homewood.

Leonard-Barton, D. (1992). Core capabilities and core rigidities: A paradox in managing new product development. Strategic Management Journal, 13(S1), 111-125. http://doi.org/10.1002/smj.4250131009

Liang, T. P., You, J. J., \& Liu, C. C. (2010). A resource-based perspective on information technology and firm performance: A meta analysis. Industrial Management \& Data Systems, 110(8), 1138-1158. http://doi.org/10.1108/02635571011077807

Meyer, K. E., Estrin, S., Bhaumik, S. K., \& Peng, M. W. (2009). Institutions, resources, and entry strategies in emerging economies. Strategic management journal, 30(1), 61-80. http://doi.org/10.1002/smj.720

Morgan, N. A., Vorhies, D. W., \& Mason, C. H. (2009). Market orientation, marketing capabilities, and firm performance. Strategic Management Journal, 30(8), 909-920. http://doi.org/10.1002/smj.764

Muchemi, A. W. (2013). Top management team diversity and performance of commercial banks in Kenya. Unpublished PhD Thesis, University of Nairobi.

Mutanen, A. (2015). Hintikka's interrogative model and a logic of discovery and justification. Acta Baltica Historiae et Philosophiae Scientiarum, 3(1). http://doi.org/10.11590/abhps.2015.1.02

Nadkarni, S., \& Barr, P. S. (2008). Environmental context, managerial cognition, and strategic action: an integrated view. Strategic Management Journal, 29(13), 1395-1427. http://doi.org/10.1002/smj.717

Nadkarni, S., \& Herrmann, P. O. L. (2010). CEO personality, strategic flexibility, and firm performance: The case of the Indian business process outsourcing industry. Academy of Management Journal, 53(5), 1050-1073. http://doi.org/10.5465/amj.2010.54533196

Nadkarni, S., \& Narayanan, V. K. (2007). Strategic schemas, strategic flexibility, and firm performance: The moderating role of industry clockspeed. Strategic Management Journal, 28(3), 243-270. http://doi.org/10.5465/amj.2010.54533196

Ndofor, H. A., Sirmon, D. G., \& He, X. (2011). Firm resources, competitive actions and performance: 
investigating a mediated model with evidence from the in-vitro diagnostics industry. Strategic Management Journal, 32(6), 640-657. http://doi.org/10.1002/smj.901

Nevis, E. C., DiBella, A. J., \& Gould, J. M. (1995). Understanding organizations as learning systems. MIT Sloan Management Review, 36(2), 73-73.

Nevo, S., \& Wade, M. R. (2010). The formation and value of IT-enabled resources: antecedents and consequences of synergistic relationships. MIS Quarterly, 163-183. http://doi.org/10.2307/20721419

Njoroge, J. G. (2015). Organizational resources and performance of mobile phone companies in Kenya (Doctoral dissertation, Kenyatta University).

Ocasio, W. (1997). Towards an attention-based view of the firm. Strategic Management Journal, 187-206. http://doi.org/10.1002/(sici)1097-0266(199707)18:1+<187::aid-smj936>3.3.co;2-b

Ocasio, W. (2011). Attention to attention. Organization science, 22(5), 1286-1296. http://doi.org/10.1287/orsc.1100.0602

Papadakis, V. M., Lioukas, S., \& Chambers, D. (1998). Strategic decision-making processes: the role of management and context. Strategic Management Journal, 19(2), 115-147. http://doi.org/10.1002/(sici)1097-0266(199802)19:2<115::aid-smj941>3.0.co;2-5

Pearce II, J.A., Robinson, R.B., \& Mital, A. (2012). Strategic management: Formulation, implementation and control. New Delhi: Tata McGraw Hill Education Private Ltd.

Penrose, E. T. (1959). The theory of the growth of the firm. New York: Sharpe.

Peteraf, M. A., \& Barney, J. B. (2003). Unraveling the resource-based tangle. Managerial and Decision Economics, 24(4), 309-323. http://doi.org/10.1002/mde.1126

Peteraf, M. A., \& Bergen, M. E. (2003). Scanning dynamic competitive landscapes: A market-based and resource-based framework. Strategic management journal, 24(10), 1027-1041. http://doi.org/10.1002/smj.325

Pfeffer, J., \& Salancik, G. R. (1978). The external control of organizations: A resource dependence perspective. New York: Harper and Row.

Rose, C., \& Thomasen, S. (2009). The impact of corporate reputation on performance. European Management Journal, 22(2), 201-210. http://doi.org/10.1016/j.emj.2004.01.012

Rose, R. C., Abdullah, H., \& Ismad, A. I. (2010). A review on the relationship between organizational resources, competitive advantage and performance. Journal of International Social Research, 3(11).

Selznick, P. (1957). Leadership in administration. New York: Harper \& Row.

Senge, P. (1990). The fifth discipline: The art and practice of the learning organization. New York: Doubleday.

Simon, H. A. (1979). Rational decision making in business organizations. The American Economic Review, 69(4), 493-513.

Spender, J. C., \& Grant, R. M. (1996). Knowledge and the firm: overview. Strategic management journal, 5-9. http://doi.org/10.1002/smj.4250171103

Srivastava, R. K., Shervani, T. A., \& Fahey, L. (1998). Market-based assets and shareholder value: A framework for analysis. The journal of marketing, 62(1), 2. http://doi.org/10.2307/1251799

Su, Z., Xie, E., Wang, D., \& Li, Y. (2011). Entrepreneurial strategy making, resources, and firm performance: evidence from China. Small Business Economics, 36(2), 235-247. http://doi.org/10.1007/s11187-009-9211-9

Sutton, R. I., Eisenhardt, K. M., \& Jucker, J. V. (1986). Managing organizational decline: Lessons from Atari. Organizational Dynamics, 14(4), 17-29. http://doi.org/10.1016/0090-2616(86)90041-0

Sveikauskas, C. D., \& Sveikauskas, L. (1982). Industry characteristics and productivity growth. Southern economic journal, 769-774. http://doi.org/10.2307/1058668

Teece, D. J., Pisano, G., \& Shuen, A. (1999). Dynamic capabilities and strategic management. In Knowledge and strategy (pp. 77-115).

Ting, H. F., Wang, H. B., \& Wang, D. S. (2012). The moderating role of environmental dynamism on the influence of innovation strategy and firm performance. International Journal of Innovation, Management and Technology, 3(5), 517. 
Van de Ven, V., \& Drazin, R. (1985). The concept of fit in contingency theory. Chapter in B. Staw and L. Cummings. Research in Organizational Behavior, 7.

Weick, K. E. (1979). Cognitive processes in organizations. Research in Organizational Behavior, 1(1), 41-74.

Wernerfelt, B. (1984). A resource-based view of the firm. Strategic Management Journal, 5(2), 171-180. http://doi.org/10.1002/smj.4250050207

\section{Copyrights}

Copyright for this article is retained by the author(s), with first publication rights granted to the journal.

This is an open-access article distributed under the terms and conditions of the Creative Commons Attribution license (http://creativecommons.org/licenses/by/4.0/). 